\title{
Corrigendum
}

\section{The influence of stress field on Li electrodeposition in Li-metal battery - CORRIGENDUM}

Vitaliy Yurkiv, Tara Foroozan, Ajaykrishna Ramasubramanian, Reza Shahbazian-Yassar, and Farzad Mashayek

doi: https://doi.org/10.1557/mrc.2018.146, Published by Materials Research Society with Cambridge University Press, 30 July 2018.

In Yurkiv et al., ${ }^{[1]}$ the information given in the Acknowledgments regarding funding from the National Science Foundation was incorrect. It should read, "Authors acknowledge the financial support from the National Science Foundation (Award No. 1805938)."

\section{Reference}

1.V. Yurkiv, T. Foroozan, A. Ramasubramanian, R. Shahbazian-Yassar, and F. Mashayek: The influence of stress field on Li electrodeposition in Li-metal battery. MRS Communications (2018). doi: 10.1557/mrc.2018.146. 